\title{
БЛИЖНЕВОСТОЧНЫЕ МАНЁВРЫ БРИТАНСКОЙ ДИПЛОМАТИИ
}

\begin{abstract}
Аннотация. В статье проанализированы особенности ближневосточного измерения британской внешней политики. В феврале 2019 г. при непосредственном участии Британии проили саммит по Ближнему Востоку в Варшаве, саммит ЕС-ЛАГ в Шарм-эль-Шейхе и конференция по Иордании в Лондоне. Руководство Соединённого Королевства демонстрирует намерение вносить вклад в безопасность и стабильность на Ближнем Востоке. Стратегические иели Великобритании в регионе противоречивы: поддерживать «ядерную сделку» с Ираном и проявлять солидарность с США, развивать тесные военные и дипломатические связи с Саудовской Аравией и выступить миротворием в Йемене. С целью подчеркнуть особую роль Британии на Ближнем Востоке в начале марта 2019 г. глава Форин Офис Дж. Хант отправился в турне по странам Персидского залива.

Ключевые слова: внешняя политика Великобритании, Дж. Хант, Ближний Восток, Европейский союз, Варшава, Египет, ЛАГ, Йемен, Иран, Иордания, Оман, радикализаџия, миграичия, помощь в развитии, «Qиаd» group, «особые отношения» с США.
\end{abstract}

\section{От Варшавы до Шарм-эль-Шейха}

Двойственность политики Великобритании, которая пока не может определить будущую форму сосуществования с европейской интеграцией, проявляется и в отношении Ближнего Востока, где желание Лондона маневрировать между союзниками соседствует с амбициями в рамках стратегии «Глобальная Британия».

Настойчиво выступая за сохранение «ядерной сделки» с Ираном наряду с Германией и Францией, Соединённое Королевство, тем не менее, поддержало своего ближайшего союзника и приняло участие в «антииранской» конференции министров иностранных дел по Ближнему Востоку, организованной под эгидой Вашингтона в Варшаве (13-14 февраля 2019 г.).

Фактически Польша провела на своей площадке международный форум, посыл которого противоречил официальной позиции ведущих стран европейской интеграции. Ещё в янваpe 2019 г. в Бухаресте Франция, Германия и Великобритания учредили Инструмент поддержки торговых расчётов (INSTEX), через который они собираются проводить транзакции за сделки между иранскими и европейскими компаниями ${ }^{1}$.

На саммите в Варшаве официальные лица от Евросоюза снизили уровень присутствия до заместителей министров иностранных дел или вовсе его проигнорировали (как это сделали представители России, Турции, Катара, Ливана, Ирана и Палестинской автономии).

В свою очередь, Лондон сместил акценты с иранской тематики на ситуацию в Йемене. С декабря 2017 г. глава Форин Офис в рамках «четвёрки» («Quad» group) вместе с коллегами из США, Саудовской Аравии и Объединённых Арабских Эмиратов (ОАЭ) обсуждают положе-

(C) Годованюк Кира Анатольевна - кандидат политических наук, старший научный сотрудник Центра британских исследований Отдела страновых исследований ИЕ РАН. Aдрес: 125009, Россия, Москва, ул. Моховая, д. 11, стр. 3. E-mail: kira.godovanyuk@gmail.com.

DOI: http://dx.doi.org/10.15211/vestnikieran22019145150

${ }^{1}$ См. подробнее: А.В. Шумилин США затягивают Европу в ближневосточные конфликты. Научно-аналитический вестник ИЕ РАН, № 1, 2019. С. 131-135. 
ние в регионе ${ }^{1}$. На полях саммита в Варшаве Великобритания возглавила эту четырёхстороннюю группу ${ }^{2}$ и подтвердила намерение поддерживать мирный процесс и искать развязки для решения гуманитарного кризиса в Йемене ${ }^{3}$.

Обозреватели писали о политическом успехе британской дипломатии в Польше, в то время как позиция США выглядела менее выигрышной: повестка конференции казалась невнятной, антииранская направленность вызывала «дискомфорт» у некоторых присутствующих 4 .

Уже через неделю Лондон попытался компенсировать репутационные потери перед странами Европейского союза на первом саммите ЕС и Лиги арабских государств (ЛАГ) в Шарм-эль-Шейхе (24-25 февраля 2019 г.) $)^{5}$. В центре внимания участников (более 40 лидеров государств, глав правительств и представителей международных организаций) были вопросы укрепления региональной безопасности. Участники саммита обсуждали общие вызовы: неупорядоченная миграция и терроризм, конфликты между Палестиной и Израилем, ситуация в Сирии, Ливии, Йемене, иранская проблема, а также вопросы экономического сотрудничества.

В Египте не произошло прорыва по тематике брекзита. Политический тупик, в котором оказалось соглашение о выходе из европейской интеграции, несколько разрядили кадры игры в бильярд премьер-премьера Италии Дж. Конте и Т. Мэй. В Египте главе британского кабинета удалось провести переговоры с ближневосточными союзниками - Саудовской Аравией, Кувейтом, Ливаном и подчеркнуть вклад Соединённого Королевства в региональную безопасность. Т. Мэй неоднократно заявляла, что стабильный арабский регион важен для Европы, а Лондон и после брекзита намерен вносить существенный вклад в безопасность континента ${ }^{6}$.

Тематика противодействия экстремизму и радикализации остается в центре британской политики на Ближнем Востоке. С 2016 г. Соединённое Королевство оказывает поддержку ${ }^{7}$ специальному центру передовых инициатив по противодействию экстремисткой идеологии «Хедая».

\section{Турне Дж. Ханта по странам Персидского залива}

Вопросы урегулирования ситуации в Йемене постепенно выходят на первый план политики Соединённого Королевства. Заметный вклад в реализацию Стокгольмского соглаше-

\footnotetext{
${ }^{1}$ Joint Statement on Yemen by the UK, UAE, Saudi Arabia and USA. 12 December 2017. URL: https://www.gov.uk/ government/news/joint-statement-on-yemen-by-the-uk-uae-saudi-arabia-and-usa (дата обращения: 30.03.2019).

2 Jeremy Hunt to chair Yemen Quad meeting on next steps in peace process. URL: https://www.gov.uk/govern ment/news/jeremy-hunt-to-chair-yemen-guad-meeting-on-next-steps-in-peace-process (дата обращения: 30.03.2019).

${ }^{3}$ В 2014 г. вооружённый конфликт в Иемене между правительственными силами и повстанцами-хуситами привёл к крупнейшему гуманитарному кризису. Коалиция арабских государств во главе с Саудовской Аравией расценила внутриполитическое противостояние в Йемене как проиранский государственный переворот и в марте 2015 г. начала военную операцию. Затяжная война в одной из самых бедных стран арабского мира привела к острой нехватке продуктов и медикаментов. По оценкам ООН, гуманитарный кризис в Йемене стал крупнейшим в мире: в феврале 2019 г. более 24 млн жителей нуждались в гуманитарной помощи, а численность внутренне перемещённых лиц превысила 3,3 млн человек. См. подробнее: https://news.un.org/ru/story/2019/02/1349421.

${ }^{4}$ In Warsaw UK builds support for Yemen ceasefire. URL: https://www.politico.eu/article/jeremy-hunt-warsaw-ukbuilds-support-for-yemen-ceasefire/ (дата обращения 30.03.2019).

5 EU-League of Arab States summit in Sharm El-Sheikh, Egypt, 24-25.02.2019. URL: https://www.consilium. europa.eu/en/meetings/international-summit/2019/02/24-25/ (дата обращения: 30.03.2019).

Press statement from the Prime Minister in Sharm el-Sheikh: 25 February 2019. URL: https://www.gov.uk/govern ment/speeches/press-statement-from-the-prime-minister-in-sharm-el-sheikh-25-february-2019 (дата обращения: 30.03. 2019).

UAE and UK sign agreement to support anti-extremism think tank. URL: https://www.thenational.ae/uae/govern ment/uae-and-uk-sign-agreement-to-support-anti-extremism-think-tank-1.221415 (дата обрашения: 30.03.2019).

${ }_{8}^{8}$ Международный центр по борьбе с экстремизмом «Хедая» открылся в Абу-Даби (ОАЭ) в 2012 г. по инициативе США под эгидой глобального антитеррористического форума. Центр стал важным хабом по обмену опытом в сфере борьбы с терроризмом и профильных исследований. В 2015 г. в Абу-Даби начал работу новый антитеррористический информационный центр «Саваб» (от. араб. «верный путь»), на который возложена задача противостоять пропаганде и агитации ИГИЛ (организация, запрещённая на территории РФ).
}

Научно-аналитический вестник ИЕ РАН, 2019, №2 
ния ${ }^{1}$ вносит спецпосланник ООН британец М. Гриффитс, который в конце января побывал в Москве и провёл переговоры с российским МИД. По инициативе Великобритании Совет Безопасности ООН в декабре 2018 г. и январе 2019 г. одобрил две резолюции ${ }^{2}$, направленные на на урегулирование конфликта.

По словам Дж. Ханта, его страна - «последняя надежда “стокгольмского процесса"». Кроме того, Лондон остаётся крупнейшим западным донором гуманитарной помощи. С начала военных действий в 2015 г. Соединённое Королевство выделило на эти цели порядка 770 млн ф.ст. На саммите в Египте Т. Мэй объявила о дополнительном транше гуманитарной помощи (200 млн ф.ст).

В начале марта 2019 г. в ходе турне по странам Персидского залива (Оман, Саудовская Аравия, ОАЭ и Йемен) глава Форин Офис продолжил работу, направленную на укрепление связей с ближневосточными партнерами ${ }^{3}$. Поездка стала первым визитом западного министра с начала йеменского конфликта ${ }^{4}$. (Руководители Форин Офиса не посещали эту страну Персидского залива с 1996 г.).

Встречаясь с официальными лицами в Йемене, глава британской дипломатии подчеркнул, что условием прекращения военных действий станет освобождение порта Ходейда от ополченцев. Представители хуситов обвинили главу МИД в искажении Стокгольмского соглашения, поскольку в документе нет упоминания о передаче порта Ходейда нейтральной стороне (о чём заявил Дж. Хант в ходе визита). Представители ополченцев добавили, что «не удивлены позицией Лондона, который занял сторону агрессора (коалиции, возглавляемой Саудовской Аравией») 5 .

Речь идёт о том, что Соединённое Королевство - крупнейший экспортёр оружия для Саудовской Аравии. В марте 2019 г. лидеры пяти крупнейших оппозиционных партий Великобритании направили письмо правительству с требованием прекратить поставки оружия Эр-Рияду и коалиции арабских государств, которые воюют против повстанцев ${ }^{6}$.

Курс на укрепление позиций на Ближнем Востоке - долгосрочная стратегия Соединённого Королевства. В ходе турне по странам Персидского залива глава британской дипломатии провёл встречи с коллегами из Саудовской Аравии и ОАЭ, обсудив взаимодействие по вопросам региональной безопасности, содействия экономическому росту и прав человека. В Омане глава Форин Офис согласовал двустороннюю британо-оманскую декларацию о партнёрстве. Несколькими неделями ранее там побывал министр обороны Великобритании Г. Уильямсон и подписал двустороннее оборонное соглашение ${ }^{7}$.

\footnotetext{
${ }^{1}$ Стокгольмское соглашение по Йемену - договорённости о прекращении огня и отводе войск из порта Ходейда для открытия гуманитарного коридора, достигнутые в ходе переговоров в столице Швеции 12-13 декабря 2018 г.

${ }^{2}$ Резолюция СБ ООН 2451 (2018) от 21 декабря 2018 г. подтверждает договорённости, достигнутые в Стокгольме, а также возлагает на ООН обязательства создать мониторинговую группу по контролю за прекращением огня. Согласно Резолюции СБ ООН 2452 (2019) от 16 января 2019 г., учреждена специальная миссия ООН в поддержку Соглашения о Ходейде на период минимум шесть месяцев.

${ }^{3}$ Foreign Secretary travels to the Gulf to boost momentum on Yemen peace process. URL: https://www.gov.uk/govern ment/news/foreign-secretary-travels-to-the-gulf-to-boost-momentum-on-yemen-peace-process (дата обращения: 30.03.2019).

${ }^{4}$ Foreign Secretary visits Yemen to bolster support for UN peace process. URL: URL: https://www.gov.uk/government/ https://www.gov.uk/government/ news/foreign-secretary-visits-yemen-to-bolster-support-for-un-peace-process (дата обращения: 30.03.2019).

5 Хуситы резко ответили на заявление главы британского МИДа. URL: https://rossaprimavera.ru/news/0ae72d93 (дата обращения: 30.03.2019).

${ }^{6}$ Opposition leaders urge government to act in Yemen crisis. URL: https://www.parliament.uk/business/news/2019/ march/opposition-leaders-urge-government-to-act-in-yemen-crisis/ (дата обращения: 30.03.2019).

${ }^{7}$ UK and Oman sign historic Joint Defence Agreement. URL: https://www.gov.uk/government/news/uk-and-omansign-historic-joint-defence-agreement (дата обращения: 30.03.2019).
} 


\section{Конференция по Иордании в Лондоне}

Иордания - ещё одна страна Ближнего Востока, с которой Британия планомерно выстраивает долгосрочное сотрудничество, руководствуясь целью трансформировать кризисные явления в политико-экономические перспективы.

Иорданское Хашимитское Королевство и Соединённое Королевство длительное время поддерживали тесные связи, хотя Амман как бывшая колония отказался присоединиться к Содружеству. В то же время страны остаются союзниками по ряду вопросов международной повестки, в частности, в борьбе против ИГИЛ в Ираке и Сирии.

С начала сирийского конфликта в Иорданию по предварительным оценкам ООН въехало около 1,3 млн беженцев. В феврале 2016 г. в Лондоне прошла конференция международных доноров «Поддержка Сирии и региона», участники которой обязались предоставить Дамаску и соседним странам, на которых легла основная нагрузка по приёму вынужденных переселенцев, 12 млрд долл.

Британия совместно с международным сообществом дала обязательства в рамках Договора по Иордании ${ }^{1}$ оказывать помощь сирийским беженцам, комбинируя гуманитарную помощь и помощь в развитии для Аммана (1,7 млрд долл.). Стратегия Лондона заключается в том, чтобы помогать сирийцам оставаться в регионе и трудоустраиваться в соседних ближневосточных странах, а не искать убежища в Европе. При непосредственном участии Великобритании Евросоюз сформулировал основную задачу иорданского пакта - преобразовать миграционный кризис в экономический рост².

Одновре́менно с этим Т. Мэй начала работу по выстраиванию двустороннего партнёрства с иорданским руководством. В ходе ближневосточного турне в ноябре 2017 г. она посетила Саудовскую Аравию и Ирак, где обсудила успехи военной операции против ИГИЛ ${ }^{3}$.

Тогда же глава британского кабинета объявила о долгосрочном партнёрстве с Иорданией с целью поддержать экономику, программные реформы и бизнес-среду, что создаст возможности для будущего торгово-инвестиционного сотрудничества двух стран ${ }^{4}$. На начальном этапе Британия предоставит 94,5 млн ф.ст. на реформу системы образования и дополнительные рабочие места 5 . Кроме того, премьер-министр предложила экспертную поддержку экономистов из Университета Оксфорда и Лондонской школы экономики. Долгосрочная цель - установить британо-иорданский диалог по экономическим реформам, который возглавят высшие официальные лица двух стран.

По словам главы департамента международной торговли П. Мордаунт, Иордания находится на передовой ближневосточного «мультикризиса», однако демонстрирует политическую стабильность. Новое десятилетнее партнёрство Лондона и Аммана будет способствовать «экономической стабильности, безопасности и процветанию».

\footnotetext{
${ }^{1}$ The Jordan Compact: A New Holistic Approach between the Hashemite Kingdom of Jordan and the International Community to deal with the Syrian Refugee Crisis. URL: https://assets.publishing.service.gov.uk/government/uploads/ system/uploads/attachment_data/file/498021/Supporting_Syria_the_Region_London_2016_-_Jordan_Statement.pdf (дата обращения: 30.03.2019).

2 The Jordan Compact: Turning the Syrian Refugee Crisis into a Development Opportunity. URL: https://leiden lawblog.nl/articles/the-jordan-compact-turning-the-syrian-refugee-crisis (дата обращения: 30.03.2019).

3 «Britain will be a partner you can depend on» - PM in Jordan. URL: https://www.gov.uk/government/speeches/ britain-will-be-a-partner-you-can-depend-on-pm-in-jordan (дата обращения: 30.03.2019).

${ }^{4}$ UK set to agree new long-term partnership to bolster Jordan's economic resilience. URL: https://www.gov.uk/govern ment/news/uk-set-to-agree-new-long-term-partnership-to-bolster-jordans-economic-resilience (дата обращения: 30.03 . 2019).

5 The UK's role in Jordan and the wider Middle East post-Brexit. URL: https://www.dlapiper.com/en/uk/insights/publi cations/2017/12/the-uks-role-in-jordan-and-the-wider-middle-east-postbrexit/ (дата обращения: 30.03.2019).
}

Научно-аналитический вестник ИЕ РАН, 2019, №2 
28 февраля 2019 г. в столице Соединённого Королевства прошла конференция «Рост и возможности, лондонская инициатива-2019» - крупнейшее международное мероприятие для поддержки инвестиций, экономического роста и рынка труда в Иордании ${ }^{1}$. Этот международный форум призван мобилизовать глобальных лидеров и бизнес-инвесторов и содействовать экономическому развитию страны.

Британский премьер подтвердила готовность Лондона передать 14 млн ф.ст. в целевой фонд Всемирного банка для экономической помощи Амману и выступить поручителем кредита Всемирного банка в размере 250 млн долл. ${ }^{2}$

\section{Выводы}

Концепция «Глобальная Британия» как ответ на системные изменения международной среды определяет Ближний Восток зоной стратегических интересов Соединённого Королевства. 29 марта 2019 г., в день, когда должен был состояться брекзит, Дж. Хант написал в «Вашингтон пост»: «Веками наша страна формировала мировые процессы, и мы продолжим это делать после выхода из ЕС. Британии останется глобальной державой» ${ }^{3}$.

Выступая за сохранение «ядерной сделки» с Ираном, Соединённое Королевство как ближайший союзник США, тем не менее, демонстрирует поддержку инициативы Вашингтона создать антииранскую коалицию.

В то же время, стремясь продемонстрировать нейтральную позицию по Ирану, Лондону удалось сместить фокус внимания с собственных политических маневров на процесс урегулирования ситуации в Йемене и укрепить военные связи с монархиями Персидского залива (Саудовская Аравия, Оман и Бахрейн, где ещё в апреле 2018 г. Британия открыла военно-морскую базу).

На Ближнем Востоке Соединённое Королевство делает ставку на развитие стратегического партнёрства с Иорданией. Страна на протяжении длительного времени демонстрирует политическую стабильность в окружении целого ряда конфликтных регионов (Ирак, Сирия и пр.) и испытывает колоссальное миграционное бремя. Выступая в качестве лидера западного мира по восстановлению иорданской экономики, Лондон решает сразу несколько задач: улучшить политических имидж в условиях репутационных потерь, связанных с брекзитом, укрепить партнёрство с наиболее стабильным государством региона, создать предпосылки для развития собственной торгово-инвестиционной политики и усилить стратегические позиции на Ближнем Востоке.

\section{Список литературы}

Годованюк К.А. Гуманитарная политика Великобритании в конфликтных зонах и постконфликтных регионах. Пути к миру и безопасности. 2018. № 1(54) Спецвыпуск: Гуманитарные вызовы, гуманитарное реагирование и защита гражданского населения в вооруженных конфликтах. Под редакцией Е.А. Степановой, 2018. С. 265-278.

Годованюк К.А. Ядерная сделка с Ираном - позиция Лондона. Научно-аналитический

\footnotetext{
${ }^{1}$ About Jordan: Growth and Opportunity - the London Initiative 2019. URL: https://www.gov.uk/government/topicalevents/iordan-growth-and-opportunity-the-london-initiative-2019/about (дата обращения: 30.03.2019).

2 Jordan Growth and Opportunity the London initiative 2019. Co-chair Statement. March 2019. URL: https://www. gov.uk/government/publications/iordan-growth-and-opportunity-the-london-initiative-2019-co-chairs-statement/jordangrowth-and-opportunity-the-london-initiative-2019-co-chairs-statement (дата обращения: 30.03.2019).

${ }^{3}$ Britain has been shaping the world for centuries. That won't change with Brexit: article by Jeremy Hunt. URL: https://www.gov.uk/government/speeches/britain-has-been-shaping-the-world-for-centuries-that-wont-change-withbrexit-article-by-jeremy-hunt Britain has been shaping the world for centuries. (дата обращения: 30.03.2019).
} 
Вестник Института Европы РАН №3. 2018. С. 106-112.

Годованюк К.А. Политика Великобритании «к востоку от Суэца». Научно-аналитический Вестник Института Европы РАН №3. 2018. С. 120-126.

Шумилин А.В. США затягивают Европу в ближневосточные конфликты. Научно-аналитический Вестник Института Европы РАН №1, 2019. С. 131-136.

\section{References}

Godovanyuk K.A. Gumanitarnaya politika Velikobritanii v konfliktnyh zonah i postkonfliktnyh regionah. Puti k miru i bezopasnosti. 2018. №1(54) Specvypusk: Gumanitarnye vyzovy, gumanitarnoe reagirovanie i zashchita grazhdanskogo naseleniya v vooruzhennyh konfliktah. Pod redakciej E.A. Stepanovoj. S. 265-278.

Godovanyuk K.A. Ydernaya sdelka s Iranom - poziciya Londona. Nauchno-analiticheskij Vestnik Instituta Evropy RAN №3. S. 106-112.

Godovanyuk K.A. Politika Velikobritanii «k vostoku ot Suehca». Nauchno-analiticheskij Vestnik Instituta Evropy RAN №3. S. 120-126.

Shumilin A.V. SSHA zatyagivayut Evropu v blizhnevostochnye konflikty. Nauchno-analiticheskij Vestnik Instituta Evropy RAN №1, 2019. S. 131-136.

\section{The Middle East Manoeuvres of British Diplomacy}

Author. Kira Godovanyuk, Candidate of Sciences (Politics), Senior Research Fellow at the UK Studies Center, Institute of Europe RAS. Address: 11-3, Mokhovaya str., Moscow, Russia, 125009. E-mail: kira.godovanyuk@gmail.com.

Abstract. The paper considers the Middle East dimension of the UK foreign policy. In February, 2019 the United Kingdom participated in the Middle East summit in Warsaw and the EULeague of Arab States summit in Sharm el Sheikh, and also hosted the international conference to support Jordan's economy. All events aimed to strengthen the UK's position in the region and demonstrated the willingness to contribute into the stability in the Middle East. Britain's controversial goals in the region can be defined as follows: to support the Iran nuclear deal along with expression of solidarity with the US, to maintain military and diplomatic ties with Saudi Arabia and to contribute to the peaceful settlement in Yemen. In March, 2019 UK Foreign Secretary had visited the Gulf countries to boost Britain's strategic position there.

Key words: UK foreign policy, J. Hunt, Middle East, European Union, Warsaw, League of Arab States, Egypt, Yemen, Iran, Jordan, Syria, Oman, radicalization, migration, development assistance, «Quad» group, UK-US special relationship.

DOI: http://dx.doi.org/10.15211/vestnikieran22019145150 